\title{
A BIBLIOTECA DO CENTRO ACADÊMICO DE VITÓRIA: Uma trajetória de responsabilidade social
}

\author{
Fernanda Bernardo Ferreira \\ Graduada em Biblioteconomia \\ Bibliotecária do Centro Acadêmico de Vitória \\ Universidade Federal de Pernambuco \\ nandabernardo@yahoo.com.br
}

Giane da Paz Ferreira Silva

Mestra em Ciência da Informação

Bibliotecária do Centro Acadêmico de Vitória

Universidade Federal de Pernambuco

gianedp@@hotmail.com

\begin{abstract}
Resumo
É papel do profissional Bibliotecário ir além da reflexão sobre responsabilidade social, vivenciando a prática de forma efetiva no dia a dia de suas atividades. Sob esse olhar, o principal objetivo deste trabalho é relatar a experiência de uma biblioteca universitária no interior do Estado de Pernambuco na promoção de ações dessa natureza. O recorte aponta dez anos (2007-2017) de práticas de responsabilidade social realizadas pelos Bibliotecários da Biblioteca do Centro Acadêmico de Vitória da Universidade Federal de Pernambuco (UFPE). Nessa perspectiva, são descritos a criação de bibliotecas para comunidade, a oferta de cursos de incentivo pré-vestibular, a inclusão sociodigital, a sustentabilidade e o uso das mídias sociais como instrumento de inserção social. Neste contexto, desenvolver ações de responsabilidade social tem sido uma prática voluntária e contínua dos Bibliotecários do Centro Acadêmico de Vitória, pois ao promoverem o bem-estar de seu público devolvem à sociedade um pouco daquilo que está sendo investido.
\end{abstract}

\section{Palavras-chave}

Responsabilidade social. Inclusão social. Bibliotecas universitárias.

\section{INTRODUÇÃO}

A responsabilidade social está presente nos mais diversos ambientes, por isso vem sendo discutida e praticada por inúmeras empresas com o objetivo de desenvolver uma consciência social e promover atividades justas e igualitárias. A responsabilidade social não se restringe apenas às empresas privadas, seu alcance perpassa pelas instituições públicas como uma ação que envolve inúmeros atores.

Nesse contexto, o conceito foi aplicado à prática biblioteconômica no que concerne à realização de atividades de forma ética e social pelos profissionais da informa- ção, quando buscam um olhar mais abrangente sobre as suas ações. (BRASIL, 2002).

$\mathrm{Na}$ Biblioteconomia, busca-se privilegiar o cumprimento da função social das unidades, sistemas e serviços de informação, com amparo nos princípios da regulamentação profissional. (MISCHIATI; VALENTIM, 2005, p. 216).

As bibliotecas desempenham papel fundamental no âmbito das universidades brasileiras, contribuindo para o desenvolvimento do ensino, da pesquisa e da extensão. A Biblioteca do Centro Acadêmico de Vitória da Universidade Federal de Pernambuco 
(UFPE), resultado da iniciativa de interiorização do ensino superior no Brasil, foi criada em 25 de setembro de 2016. A unidade promove há mais de uma década a democratização do acesso à informação com a oferta de serviços para toda a comunidade acadêmica da instituição e a sociedade em geral. Nessa perspectiva, atua como mediadora da informação entre os mais diferentes públicos, com um acervo de mais de 25 mil exemplares e disponibiliza acesso a produtos e serviços de informação nos mais diversos suportes.

Esse artigo trata-se de um relato de experiência visando apresentar as ações de responsabilidade social realizadas pela Biblioteca do Centro Acadêmico de Vitória no período de 2007 a 2017. Nesse intuito, como metodologia foi delineada uma pesquisa documental (GIL, 2008), baseada na utilização e análise de fontes documentais, tais como documentos oficiais, relatórios anuais, projetos de extensão, fotografias e artigos produzidos pela Biblioteca desde sua criação.

Como ponto de partida, a abordagem a seguir visa caracterizar a responsabilidade social e suas implicações na atuação do profissional Bibliotecário, culminando com a descrição das ações sociais realizadas pela biblioteca universitária e de suas repercussões na sociedade.

\section{RESPONSABILIDADE SOCIAL}

A palavra responsabilidade deriva do latim respondere, cuja tradução é responder. Segundo Ferreira (2000, p. 402), responsabilidade é a "obrigação de responder pelas ações próprias, pelas dos outros ou pelas coisas confiadas." Etimologicamente a palavra social origina-se do latim sociälis e apresenta como significado aquilo "que diz respeito à sociedade; que tem tendência para viver em sociedade; que diz respeito a uma sociedade comercial.” (FERREIRA, 2000, p.462).

De acordo com Ferreira (2015, p. 14), "A responsabilidade social associa-se a ética e a conceitos de modificações, visando o bem-estar do ser humano." Elas cami- nham juntas na busca por um ambiente justo. Assim, a responsabilidade social busca o equilíbrio e, principalmente, objetiva a melhoria da qualidade de vida da sociedade nos mais diversificados contextos.

Ashley et al. (2002, p. 6) definem a responsabilidade social como "toda e qualquer ação que possa contribuir para a melhoria da qualidade de vida da sociedade."

Segundo a Norma Brasileira 16001 da Associação Brasileira de Normas Técnicas (ABNT, 2004), fundamenta-se na metodologia conhecida como Plan-Do-Check-Act (PDCA) ou planejar, fazer, verificar e atuar, descrita como:

Planejar (Plan): estabelecer os objetivos e processos necessários para se produzirem resultados em conformidade com a política da responsabilidade social da organização;

Fazer $(D o)$ : implementar os processos;

Verificar (Check): monitorar e medir os processos em relação à política de responsabilidade social e aos objetivos, metas, requisitos legais e outros, e reportar os resultados; Atuar (Act): tomar ações para melhorar continuamente o desempenho ambiental, econômico e social do sistema da gestão. (ABNT, 2004, p. VI).

A Norma Brasileira 16001 (2004) estabelece seguimentos aplicados a todas as empresas, requisitos que priorizem a gestão $\mathrm{da}$ responsabilidade social, permitindo a prática de seus compromissos éticos e sua preocupação com a cidadania; o desenvolvimento sustentável; e a transparência das suas atividades.

\subsection{Responsabilidade social do Bibliote- cário}

É papel do profissional Bibliotecário não apenas refletir sobre a responsabilidade social, mas colocá-la em prática no dia a dia de suas atividades.

De acordo com Moraes e Lucas (2012), a responsabilidade social nesse con- 
texto surge simultaneamente com a responsabilidade social empresarial, porém com um olhar voltado para o acervo e suas demandas.

[...] a Responsabilidade Social do Bibliotecário deixa de ser centrada na organização do acervo para dar conta, cada vez mais, dos processos de mediação da informação, e o objeto de preocupações da Biblioteconomia. (MORAES; LUCAS, 2012, p. 115).

Conforme considerado pelas autoras, o profissional Bibliotecário amplia sua forma de agir, buscando promover não apenas o acervo e a estrutura da instituição, mas volta sua atenção à disseminação da informação, uma vez que esta passa a ser o instrumento necessário à transformação social, tornando assim o Bibliotecário não apenas um mediador de informações, mas um mediador cultural.

Cunha (2003) reflete sobre algumas premissas essenciais ao desenvolvimento do papel social desse profissional, destacando o atendimento às necessidades de informação dos cidadãos; o auxílio na conquista de direitos e deveres; o atendimento às necessidades informacionais dos pesquisadores, que contribuem para o progresso científico; o incentivo à leitura dos alunos; e a participação efetiva ao definir as políticas.

A Biblioteconomia é, pois, "[...] uma profissão essencialmente social, uma profissão de contato, de 'fazer com o outro', de fazer para o outro." (CUNHA, 2003, p. 43, grifo do autor). Isso evidencia o quanto é fundamental o Bibliotecário como ator social buscar satisfazer a necessidade do usuário e contribuir para uma sociedade consciente não apenas das informações que busca, mas da existência da ampla oferta de bens informacionais que são importantes na construção e no reconhecimento de seus direitos.

É inegável a importância da informação para o desenvolvimento da sociedade como um todo, como de cada cidadão em particular. Num período como o que hoje vivenciamos, onde a informação tornou-se o insumo básico para a tomada de decisões em qualquer nível, o papel dos profissionais da informação e, particularmente, dos bibliotecários é fundamental. (CUNHA, 2003, p. 45).

Segundo Ferreira (2015), a responsabilidade social do profissional Bibliotecário vai além das condições de espaço físico da biblioteca, pois está presente quando desempenha seu papel na disponibilização da informação correta e eficiente, na realização de ações que contribuam para o desenvolvimento da comunidade em que está inserido e na realização de atividades que almejam a melhoria dos serviços por ela oferecidos.

\subsection{Código de Ética Profissional Biblio- tecário}

De modo geral, o Código de Ética constitui-se no conjunto de normas e condutas voltadas para o profissional Bibliotecário, que contribui para a tomada de decisões no exercício da profissão, com o intuito de fornecer suporte e orientação, focados na ética e em seus preceitos, de forma a colaborar com o desempenho de atividades justas.

Formado por direitos e deveres, o Código de Ética contribui para o aperfeiçoamento das ações pautadas em leis que permitem desempenhar suas funções de forma a proporcionar um olhar voltado não apenas à prática tecnicista do trabalho, mas um olhar humanizado, que valoriza as boas condutas e o bom relacionamento entre profissionais e usuários.

A Biblioteconomia, não constituindo exceção à regra, procurou garantir à sociedade, por meio da criação de princípios éticos biblioteconômicos, que as atividades desenvolvidas por seus profissionais não representem interesses pessoais, mas sim, signifiquem uma efetiva contribuição à coletividade. (MISCHIATI; VALENTIM, 2005, p. 211).

De acordo com as autoras, a Biblioteconomia caracteriza-se como uma profis- 
são voltada à prestação de serviços de informação e, portanto, torna-se mediadora entre o usuário que a utiliza e quem produz a informação. Desta forma, evidencia a relevância das competências e habilidades dos profissionais nos mais diversificados contextos, científico, técnico, tecnológico e social, com o intuito de alcançar o objetivo social e ético que a profissão evidencia.

[...] os Bibliotecários devem coletar e fornecer, sem quaisquer tipos de restrições, todas as informações necessárias a seus usuários, sem questionar a aplicação que eles farão das informações recebidas. (VERGUEIRO, 1994, p. 9).

Observa na fala do autor a importância do profissional na realização de suas atividades sem preconceitos, voltado para um atendimento eficaz e consciente das diferentes necessidades apresentadas pela clientela, e fundamentado em um olhar criterioso e sem restrições.

\subsection{A responsabilidade social na biblio- teca universitária}

A biblioteca universitária é responsável pelas atividades de organização, tratamento, recuperação e disseminação da informação, bem como pela promoção de conhecimentos de diferentes áreas nos mais variados suportes, na medida em que buscar disponibilizar serviços e produtos informacionais para a comunidade acadêmica. Portanto, o Bibliotecário torna-se o elo entre a informação e o usuário, colaborando para o surgimento do vínculo e do crescimento informacional no contexto acadêmico, por permitir a troca do conhecimento através dos diferentes pontos de acesso, o que vem a contribuir para o enriquecimento dessa convivência e das atividades desenvolvidas.

As constantes evoluções tecnológicas permitiram diversas transformações nas bibliotecas no decorrer dos anos, que possibilitam aos seus usuários maior facilidade na busca por informações em tempo hábil. A relação entre Bibliotecário e usuários tam- bém se modifica e, com isso, a biblioteca universitária amplia sua forma de servir.

Carvalho (2004) relata sobre a abertura de novas possibilidades das bibliotecas universitárias, impulsionadas pelos avanços na ciência e tecnologia, em proporcionar mudanças socioeconômicas, culturais e educacionais. Tais transformações permitem aos usuários adquirir conhecimentos e usá-los de diferentes formas.

Segundo Tarapanoff (1982, p.73), "[...] a biblioteca absorve, reflete e reprocessa as características da organização à qual pertence." Esta afirmação evidencia de forma clara a participação efetiva e social da biblioteca na atividade da comunidade em que se encontra inserida, de forma a desempenhar suas atividades com um olhar responsável, que contribui para o desenvolvimento da academia e da comunidade.

[...] a cada demanda de informação com o objetivo de disponibilizar e acessibilizar a informação, aceitando multiplicidade e diversidade de acervos, de profissionais e usuários, de produtos e serviços, de estruturas organizacionais e outras mais. (CARVALHO, 2004, p.26).

Tarapanoff (1982, p.74) aponta algumas características próprias das ações universitárias, destacando que "a primeira característica geral da universidade é o de ser uma organização ou sistema social.".

Segundo Parsons (1960 apud TARAPANOFF, 1982), qualquer sistema social é total ou parcialmente constitutivo da sociedade. Assim, a Universidade é vista como um produto da sociedade da qual faz parte. Evidencia como principal característica o tratamento voltado para o social, uma organização com propósitos e serviços voltados totalmente para o homem. Destaca como principal responsabilidade a socialização dos membros participantes desta sociedade no contexto e nas funções que irão desempenhar. $\mathrm{O}$ autor demonstra um olhar social que ultrapassa as estruturas físicas no âmbito universitário e expande para os contornos de suas delimitações. 
De acordo com Carvalho (2004), a biblioteca universitária é vista como um espaço de aprendizagem, que deve buscar o aperfeiçoamento contínuo sem perder sua relação com a socialização do conhecimento.

\section{AÇÕES DE RESPONSABILIDADE SOCIAL NA BIBLIOTECA DO CEN- TRO ACADÊMICO DE VITÓRIA}

A Biblioteca do Centro Acadêmico de Vitória apresenta-se como elo de informação e de responsabilidade social, ao desenvolver atividades que vão além do cenário Biblioteconômico e universitário. Ela expande suas ações para o contexto social, promovendo atividades com o objetivo de contribuir para a participação social na gestão de atividades, e, ao mesmo tempo, incentivar, viabilizar e afirmar a participação da biblioteca universitária nesse processo por intermédio do desenvolvimento de diversos projetos e ações sociais.

\section{a) Biblioteca Comunitária}

Com o objetivo de envolver diversos segmentos da sociedade na defesa do pluralismo, do respeito às diferenças, e na luta pela igualdade de direitos das pessoas, a Biblioteca do Centro Acadêmico de Vitória firmou parceria com a organização não governamental "A Cia. dos 10". Essa organização atua como companhia de teatro, sendo responsável por promover atividades de artes cênicas, espetáculos e atividades afins no Município de Vitória de Santo Antão.

A parceria permitiu angariar junto à comunidade acadêmica doações de cerca de 1.500 livros de literatura infanto-juvenil, resultando na criação de uma biblioteca comunitária no prédio da antiga Estação Ferroviária, que passou a ser um espaço de leitura, aprendizado e conhecimento, que promove a inclusão da comunidade em eventos culturais e de lazer.

\section{b) Projeto "Clicav: um olhar digital"}

O Projeto de extensão "Clicav: Um olhar digital" tem o objetivo de promover a inclusão sociodigital, por intermédio da oferta de minicursos de informática para jovens $\mathrm{da}$ comunidade circunvizinha interessados em desenvolver habilidades em informática. Buscando promover uma educação inclusiva para facilitar o acesso à informação digital, o Clicav ocorreu no período de 2009 a 2015, como uma ação extensionista da Biblioteca do Centro Acadêmico de Vitória - UFPE.

Registrado na Plataforma do Sistema de Gestão de Projetos- SIGPROJ do Ministério da Educação (MEC), até sua sexta versão, este projeto ofertou 18 minicursos, beneficiando um público de 492 jovens e adolescentes de cidades do interior de Pernambuco. Como resultados a ação de extensão permitiu aos jovens vivenciar o mundo digital, passando a manipular o computador e utilizar as ferramentas tecnológicas. Do mesmo modo, proporcionou aos participantes a oportunidade de conhecer e se aproximar do ambiente universitário, conforme ilustra a Figura 1.

Figura 1: Projeto de extensão Clicav

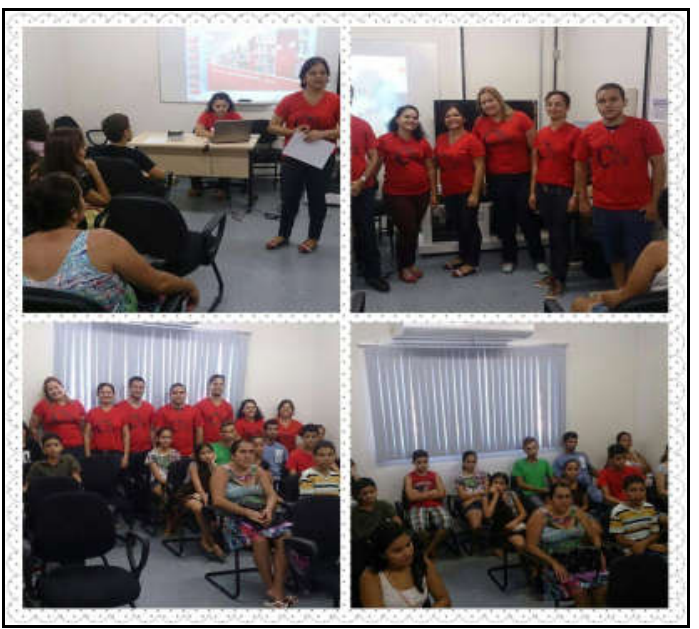

Fonte: UFPE (2015).

c) Biblioteca "Espaço Sementes"

A Gerência Regional de Educação (GRE), em parceria com a Biblioteca do Centro Acadêmico de Vitória, implantou, nas suas dependências, a biblioteca "Espaço Sementes", que teve suas atividades iniciadas em 17 de agosto de 2016 (FIGURA 2).

Numa ação integrada, a participação da Biblioteca foi primordial na concepção do 
layout físico, na implantação de um software livre para gerenciamento da coleção, no desenvolvimento de um sistema de classificação para o acervo e no treinamento da equipe.

Figura 2 Espaço Sementes (GRE)

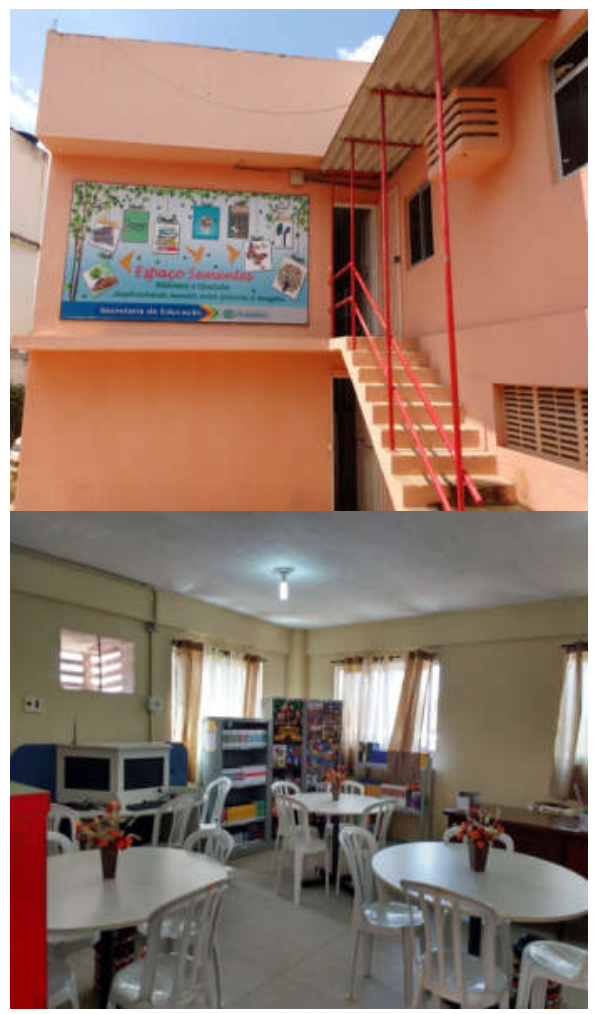

Fonte: UFPE (2016).

d) Projeto "Papa Pilhas": meio ambiente, sustentabilidade e questão socioambiental

O projeto "Papa Pilhas" é uma ação de preservação ambiental que promove a sustentabilidade no âmbito da Universidade, ao disponibilizar recipientes para coletar de pilhas e matérias afins. Um dos coletores foi instalado dentro da Biblioteca para possibilitar o descarte correto dos resíduos, visando atender ao Decreto 5.940 de coleta seletiva em órgãos públicos. (BRASIL, 2006).

Após a coleta, os resíduos são destinados para as cooperativas de catadores da cidade, que realizam coleta semanalmente. Essa iniciativa contribuiu para a conscientização sobre as práticas ambientais e educativas de preservação do meio ambiente na comunidade acadêmica.

\section{e) Ações de acessibilidade}

Considerando que as bibliotecas, sobretudo as universitárias, precisam estar bem inseridas nas questões de acessibilidade para seus usuários, um fato marcante foi a inserção do Núcleo de Acessibilidade (Nace) no espaço físico da Biblioteca. Esse cenário concorreu para que alguns servidores realizassem o "Curso de Libras" com o intuito de oferecer serviços adequados.

Essas ações necessitam ser expandidas e, nesse sentido, através da iniciativa do Nace em parceria com a Biblioteca, foi elaborado um questionário aplicado à comunidade acadêmica para identificar as necessidades da comunidade e a partir daí promover o "Curso de Libras Básico" para os demais profissionais do Campus Acadêmico. A iniciativa está em sintonia com a principal atribuição do Nace: promover acessibilidade e inclusão educacional de pessoas com deficiência e outras necessidades específicas no âmbito da UFPE, atuando em parceria com os diversos setores da Universidade.

Entre suas ações prioritárias, encontra-se $\mathrm{o}$ estímulo à formação continuada de recursos humanos com foco na abordagem de pessoas com deficiência. $\mathrm{O}$ curso será oferecido com duração de um mês, buscando proporcionar aos participantes a ampliação dos serviços para o público da universidade, colaborando para prestação de um serviço de qualidade e que preza pelo bem-estar de seus usuários.

Outro destaque está na parceria feita com a Fundação Dorina Nowill para cegos, que tem permitido o recebimento de doação de livros em Braille, falados e digitais, proporcionando uma biblioteca socialmente inclusiva para pessoas com deficiência visual e baixa visão.

\section{f) Projeto "Cine Bibcav"}

A Biblioteca do Campus Vitória amplia suas atividades e promove aos seus 
usuários a apresentação de vídeos sobre diferentes temáticas, e também a exposição de poesias de artistas locais, conforme Figura 3. O "Cine Bibcav" é uma proposta de atividade cultural pedagógica desenvolvida pela Biblioteca e tem como principal objetivo promover as atividades culturais, de ensino, pesquisa e extensão, utilizando mídias audiovisuais.

Essas ações possibilitaram a interação cultural e a divulgação da cultura do município, valorizando o trabalho artístico e cultural daqueles que contribuem para o acesso à cultura e a promoção cultural de nosso povo.

Figura 3 - Exposição cultural

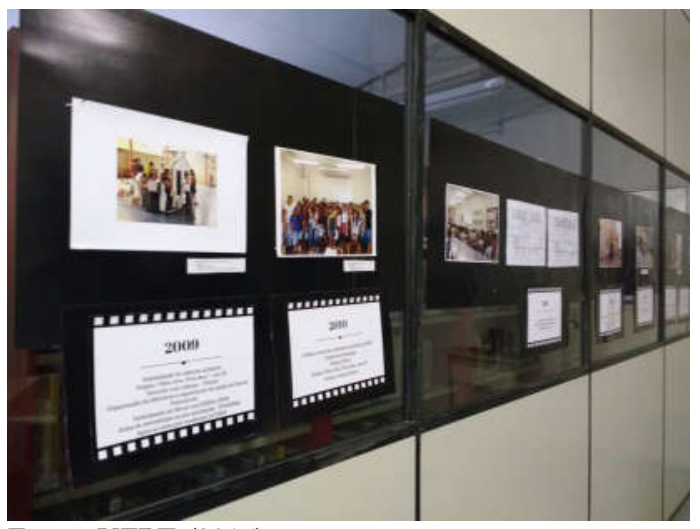

Fonte: UFPE (2016).

\section{g) Projeto "Obra viva, Viva obra!"}

O Projeto "Obra viva, Viva obra!" teve início em 2006, objetivando despertar o interesse pela leitura através da realização de oficinas e promoção de eventos artísticos e culturais que integram alunos de várias escolas do Município de Vitória de Santo Antão.

Acontecendo de forma itinerante, o projeto conseguiu realizar mais de 20 oficinas de leitura e recitais de poesias dramatizados, sempre tentando despertar talentos locais e inserir a comunidade em eventos culturais e de lazer. Realizou atividades com a participação de professores da rede pública municipal e alunos de várias escolas da rede pública e privada do Município de Vitória de Santo Antão, compreendendo um total de mais de 240 pessoas. (SILVA et al., 2010).

O projeto foi essencial na divulgação de atividades culturais e de lazer para a comunidade, além de estimular o hábito de leitura e o estímulo de aprendizagem contínua.

\section{h) Promoção da informação nas redes sociais}

As redes sociais surgem como importantes meios de comunicação e ferramentas do serviço de referência, sendo impossível negar a forma como influenciam e mudam a vida e rotina das pessoas, seja pela agilidade de comunicação, interação ou poder de atração.

Como forma de apresentar e divulgar algumas das atividades realizadas pela Biblioteca do Centro Acadêmico de Vitória, foram criadas plataformas para estabelecer o serviço de referência em ambientes digitais, com a divulgação de informações à comunidade acadêmica e à que está em seu entorno.

O serviço de referência na era digital traz na essência os mesmos preceitos do serviço presencial, porém, integra a possibilidade de servir como portal para outras fontes de informação atraindo um maior número de usuários e auxiliando na recuperação da informação em menor tempo. Nessa perspectiva, a Biblioteca está conectada através da bomepage (www.ufpe.br/bibcav), do Facebook e do canal no Youtube. (SILVA et al, 2014).

$\mathrm{Na}$ homepage, é possível ter acesso a informações sobre os serviços, os contatos e os projetos desenvolvidos pela Biblioteca. Sua gerência cabe a dois servidores da Biblioteca que podem produzir conteúdo específico para essa plataforma.

Como forma de tornar a página da Biblioteca mais atrativa aos seguidores e atrair novos, foram definidas algumas estratégias para manutenção e vivacidade. $\mathrm{O}$ ponto de partida foi o estabelecimento de uma agenda das principais temáticas a serem tratadas na rede social. 
O canal de vídeos no Youtube, que também está vinculado a conta do Google, foi criado para que possam ser disponibilizados materiais de apoio ao usuário; lá é possível acompanhar campanhas de preservação do acervo, regras básicas para utilização dos espaços da Biblioteca, além de tutoriais para formatação de trabalhos de conclusão de curso de acordos com as normas da ABNT. As sugestões dos temas abordados podem vir dos próprios usuários com indicações diretas. Os tutoriais são feitos no programa "Cantasia Studio" e disponíveis as sextasfeiras no canal do Youtube, bem como no Facebook da Biblioteca, conforme Figura 4. (UNIVERSIDADE FEDERAL DE PERNAMBUCO, 2017).

Figura 4 - Divulgação da informação em Rede

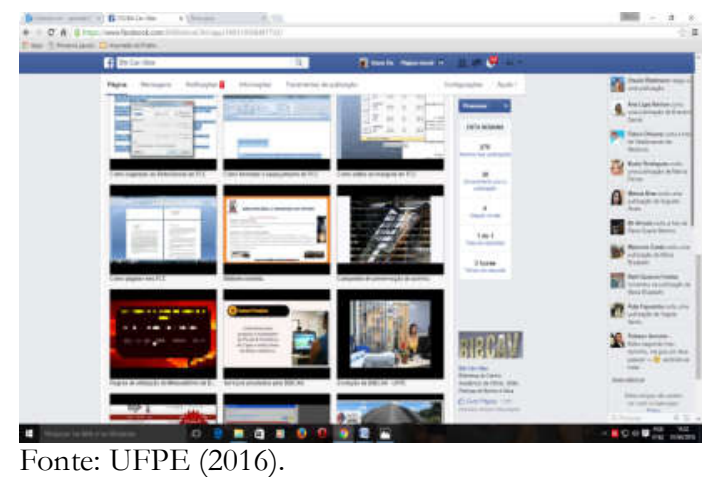

A Biblioteca mantém também conta do Instagram, criada em maio de 2017 para aproximar ainda mais a instituição e os seus usuários, mas não segue um rigor de agenda quanto os demais canais. Tende a ser uma forma de interação de cunho jornalístico e despojado acerca das notícias e eventos pertinentes da Biblioteca e do Centro. (UNIVERSIDADE FEDERAL DE PERNAMBUCO, 2017).

\section{i) Campanhas de doações de livros}

Inúmeras cidades do interior de Pernambuco tiveram suas bibliotecas escolares atingidas pelas enchentes ocorridas em maio de 2017, tendo seu acervo danificado. Em parceira com outras instituições, a Biblioteca do Centro Acadêmico de Vitória participa da campanha intitulada "Livro solidário", para a arrecadação de livros para as bibliotecas de 40 escolas estaduais e 200 municipais, que foram atingidas pela enchente na Mata Sul de Pernambuco.

Essa ação promove nas pessoas o ato solidário e a ação social ao divulgar conhecimento e promover a informação a todos, independentemente de onde quer que estejam.

\section{j) Projeto CAVinho}

O CAVinho ocorre como projeto de extensão do Centro Acadêmico de Vitória e objetiva oferecer aulas de reforço às crianças com idade entre 7 e 12 anos da comunidade do entorno do Campus. Anualmente, 25 crianças são selecionadas para participar da ação.

Nas aulas os alunos veem conteúdos de diversos campos do conhecimento, tais como matemática, português, biologia e educação física, dentre outros.

As aulas ocorrem nas dependências da Biblioteca, que integra o projeto colaborando na programação de atividades culturais, estimulando o hábito da leitura, além de selecionar e exibir filmes infantis e educativos.

\section{k) Projeto CAVest}

O projeto Curso Pré-vestibular do Centro Acadêmico de Vitória (CAVest) promove aulas pré-vestibulares a partir da parceria entre os cursos do Centro e a Biblioteca.

Nesse período, mais de mil estudantes foram contemplados e vários realizaram o sonho de ingressar numa universidade. Neste sentido, o papel da Biblioteca consiste na disponibilização de um acervo de ensino médio, no cadastramento dos participantes e no acesso aos serviços oferecidos. Dessa forma, a unidade colabora com o incentivo à formação acadêmica e com a melhoria do ensino para os alunos que desejam adentrar na vida universitária, concorrendo, assim, 
para o desenvolvimento informacional da sociedade.

\section{CONCLUSÃO}

A Biblioteca do Centro Acadêmico de Vitória vem buscando sempre a excelência no atendimento. aos seus usuários. Através de pesquisa de opinião, foi considerada pela maioria de seus visitantes como um espaço acolhedor, propício ao estudo e à leitura, representando, para muitos, o coração da Universidade. Esse pulsar tem sido inspirador na oferta de novos serviços e se reflete no espírito de trabalho em equipe. Por essa razão, participar da vida acadêmica e administrativa do Centro, com o apoio irrestrito da administração e dos demais atores envolvidos no processo, tem sido uma oportunidade constante de desenvolver ações estratégicas visando o sucesso do Campus da UFPE em Vitória de Santo Antão.
Os resultados das ações sociais desenvolvidas representam um marco na vida de todos os participantes, seja pela troca de experiências e saberes, seja pelas possibilidades de atividades em uma biblioteca universitária.

Experiências dessa natureza integram a rotina das instituições comprometidas com o fazer social e demonstram como a responsabilidade social do Bibliotecário torna-se essencial no desenvolvimento destas ações, possibilitando aos indivíduos o acesso à informação e ao conhecimento.

Sob esse olhar, apresentar as ações sociais realizadas pela Biblioteca do Campus Vitória e, principalmente pelo profissional Bibliotecário, como forma de divulgação e de instrumento de responsabilidade social, é, sem dúvida, uma forma de devolver à sociedade um retorno daquilo que está sendo investido na unidade.

\title{
THE LIBRARY OF THE ACADEMIC CENTER OF VITORIA: A trajectory of social responsibility
}

\begin{abstract}
It is the role of the professional Librarian to go beyond the reflection on social responsibility, experiencing the practice in an effective way in the day to day of its activities. Under this view, the main objective of this work is to report the experience of a university library in the interior of the State of Pernambuco (Brazil) in the promotion of actions of this nature. The clipping points ten years (2007-2017) of social responsibility practices carried out by the Librarians of the Library of the Academic Center of Vitória de Santo Antão of the Federal University of Pernambuco (UFPE). In this perspective, the creation of community libraries, the provision of pre-university entrance courses, social-digital inclusion, sustainability and the use of social media as an instrument of social insertion are described. In this context, developing social responsibility actions has been a voluntary and continuous practice of the Librarians of the Academic Center of Vitoria, because in promoting the well-being of their public, they give back to society a little of what is being invested.
\end{abstract}

Keywords

Social responsibility. Social inclusion. University libraries.

Artigo recebido em 04/06/2018 e aceito para publicação em 15/08/2018

\section{REFERÊNCIAS}

ASHLEY, P. Ética e responsabilidade social nos negócios. São Paulo: Atlas, 2003.

ASSOCIAÇÃO BRASILEIRA DE NORMAS TÉCNICAS. NBR ISO 16000. Diretrizes sobre Responsabilidade social. São Paulo, 2010. Disponível em:
$<$ http://www.inmetro.gov.br/qualidade/res ponsabilidade_social/norma_nacional.asp $>$. Acesso em: 21 set. 2017.

BRASIL. Resolução CFB N. ${ }^{\circ}$ 42, de 11 de janeiro de 2002. Dispõe sobre Código de Ética do profissional Bibliotecário. Diário Oficial da União Brasília, DF, 14 jan. 2002. Disponível em:

$<$ http://presrepublica.jusbrasil.com.br/legis 
lação/128675/lei-4084-62>. Acesso em: 19 set. 2017.

BRASIL. Decreto $\mathbf{N}^{\circ} \mathbf{5 . 9 4 0}$, de 25 de outubro de 2006. Institui a separação dos resíduos recicláveis descartados pelos órgãos e entidades da administração pública federal direta e indireta, na fonte geradora, e a sua destinação às associações e cooperativas dos catadores de materiais recicláveis, e dá outras providências. Diário Oficial da União, Brasília, DF, 26 out. 2006. Seção 1, p. 4. Disponível em:

$<$ http://www2.camara.leg.br/legin/fed/dec ret/2006/decreto-5940-25-outubro-2006546076-publicacaooriginal-59771-pe.html>. Acesso em: 09 ago. 2018.

CARVALHO, I. C. L. A socialização do conhecimento no espaço das bibliotecas universitárias. Niterói: Intertexto; Rio de Janeiro: Interciência, 2004.

CUNHA, M. V. O papel social do Bibliotecário. Encontros Bibli: revista eletrônica de Biblioteconomia e Ciência da Informação, Florianópolis, v. 8, n. 15, 2003. Disponível em:

$<$ https://periodicos.ufsc.br/index.php/eb/ article/viewFile/1518-

2924.2003v8n15p41/5234>. Acesso em: 10 out. 2017.

FERREIRA, A. B. H. Dicionário da Língua Portuguesa Miniaurélio. 4. ed. Rio de Janeiro: Nova Fronteira, 2000.

FERREIRA, F. B. A biblioterapia como instrumento de responsabilidade social do profissional bibliotecário: visão de alunos pré-concluintes. 2015. 92 f. Monografia (Graduação em Biblioteconomia) UFPB, João Pessoa, 2015.

GIL, A. C. Métodos e técnicas de pesquisa social. São Paulo: Atlas, 2008.

MISCHIATI, A. C.; VALENTIM, M. L. P. Reflexões sobre a ética e a atuação profissional do Bibliotecário. Transinformação, Campinas, v.17, n.3, p. 209-220, set./dez.,
2005. Disponível em:

$<$ http://periodicos.puc-

campi-

nas.edu.br/seer/index.php/transinfo/article /view/686>. Acesso em: 28 out. 2017.

MORAES, M. B.; LUCAS, E. O. A responsabilidade social na formação do bibliotecário brasileiro. Em Questão, Porto Alegre, v. 18, n. 1, p. 109-124, jan./jun. 2012. Disponível em:

$<$ http://seer.ufrgs.br/index.php/EmQuesta o/article/view/24107/19763 >. Acesso em: 11 out. 2017.

TARAPANOFF, K. A biblioteca universitária vista como uma organização social. Estudos avançados em Biblioteconomia e Ciência da Informação, Brasília, v. 1, n. 1, p. 73-92, 1982. Disponível em:

$<$ http://www.brapci.ufpr.br/brapci/v/a/32 04>. Acesso em: 04 out. 2017.

UNIVERSIDADE FEDERAL DE PERNAMBUCO. Centro Acadêmico de Vitória. Biblioteca Setorial. Manual de serviços da biblioteca setorial do Centro Acadêmico de Vitória de Santo Antão 2016. Vitória de Santo Antão: UFPE, 2017.

Relatório anual da biblioteca setorial do Centro Acadêmico de Vitória de Santo Antão 2013. Vitória de Santo Antão: UFPE, 2015.

Relatório anual da biblioteca setorial do Centro Acadêmico de Vitória de Santo Antão 2015. Vitória de Santo Antão: UFPE, 2016.

. Relatório anual da biblioteca setorial do Centro Acadêmico de Vitória de Santo Antão 2016. Vitória de Santo Antão: UFPE, 2017.

SILVA, G. P. F. et. al. Interiorização do ensino superior e a participação das bibliotecas na extensão universitária. In: FÓRUM DE EXTENSÃO, PESQUISA E ENSINO, E X ENCONTRO DE EXTENSÃO, 3., 2010, Recife. Anais... Recife: UFPE, 2010. 
SILVA, G. P. F. et al. O poder das redes sociais na prática do serviço de referência em bibliotecas universitárias. In: SEMINÁRIO NACIONAL DE BIBLIOTECAS UNIVERSITÁRIAS,18., 2014, Belo Horizonte. Anais... Belo Horizonte: UFMG, 2014.
VERGUEIRO, W.C.S. Ética profissional versus ética social: uma abordagem sobre os mitos da biblioteconomia. Palavra-Chave, São Paulo, n. 8, p. 8-11, 1994. Disponível em:

$<$ http://abecin.org.br/data/documents/Pal avra_Chave_8.pdf $>$. Acesso em: 04 out. 2017. 